This is an Author's Accepted Manuscript of an article published in College \& Undergraduate Libraries, 2008, v.15(1/2), copyright Taylor \& Francis, available online at: http://www.tandfonline.com/ DOI: 10.1080/10691310802177101.

\title{
Critical Thinking is a Life Relevancy: A Hospitality Management Student Case Study
}

\author{
Monica Berger
}

\begin{abstract}
This article describes a library workshop for freshman hospitality management students enrolled at New York City College of Technology, CUNY, which features a focus on critical thinking. An active learning experience uses an element of surprise. Students evaluate the website of a bankrupt company where information about the company's situation is hidden or not present. When the instructor guides the class to find unbiased information from newspapers, many students begin to think critically about sources.
\end{abstract}

KEYWORDS. Critical thinking, information literacy, hospitality management, evaluating websites, library instruction

Monica Berger MLS, MA, is Assistant Professor and Technical Services and Electronic Resources Librarian, New York City College of Technology Library, City University of New York, Brooklyn, NY 11201 (address email to: mberger@citytech.cuny.edu).

\section{INTRODUCTION}

A focus on developing critical thinking skills and information literacy competency is emerging in the profession. When my hospitality management freshmen workshop transitioned from traditional bibliographic instruction to instruction that integrated information literacy, critical thinking about information became a primary learning objective. Critical thinking about information is specifically "determining the reliability of a source," (Goad 2002, 73) and otherwise evaluating information. Rather than using a checklist or purely analytical approach, critical thinking about information is infused throughout the session.

Early in the session, after students participate in an active-learning approach to research, the author creates a specific moment that for some students results in a moment of self-awareness that may encourage students to develop critical thinking skills. Through this exercise, which involves an element of surprise, students may be affected on an emotional as well as intellectual level where they can begin to see the relationship between their personal welfare and their ability to think critically. Specifically, students need to learn that there is a connection between how they evaluate information and life relevancy issues such as finding and keeping a good job. 
After several years of teaching one-shot library skills workshops to Hospitality Management freshmen at New York City College of Technology, there was a need to change my teaching style, and, more importantly, incorporate classroom experiences that were fresh and exciting. Google reigned triumphant and students were increasingly unenthusiastic about the library workshop. Hospitality management students can be challenging because many have come to college with very clear professional goals that preclude learning how to use a library and do research. Many of the hospitality freshmen have never used any library whatsoever.

At New York City College of Technology, City University of New York, also known as City Tech, there is often a disconnect between the library and the reality of student life which often includes a full-time job and family responsibilities (although students are increasingly traditional college-age and full-time students). City Tech, with a student population of 12,223 in fall 2005, is a comprehensive four-year college, and it offers predominantly two-year degrees. Institutional research found $51 \%$ of the students were born outside of the United States, $63 \%$ are the first in their families to attend college, and 60\% report speaking a language other than English at home. Nearly $80 \%$ of first year students receive need-based financial aid.

\section{THE LIBRARY WORKSHOP}

Library sessions for the freshmen hospitality students are sixty to seventy-five minutes long and begin with student-oriented active learning. Students are asked to explore how they would solve a "real life" problem: preparing for an interview and choosing an employer. This exercise closely matches the assigned research project--a three-page research paper comprised of a company profile (referred to as an industry profile in the syllabus). The assignment reflects how the entire course is oriented towards career exploration. Although one of the assigned companies could be selected for the library workshop, we use instead a well-known company that is undergoing bankruptcy. The first year the Trump Taj Mahal was selected, followed by airlines such as United Airlines and Delta Air Lines. Students are almost universally ignorant of the financial status of these companies.

The class begins with a discussion of how the students will prepare for the job interview. Some students offer the suggestion of contacting someone within the company. We discuss the limitations as well as the pros and cons of personal contacts but students agree that they need more objective information. With the occasional exception, students always choose to use the company's website. We spend considerable time exploring the company's website and discuss at length the audience for the website, the currency of the website, if the website is promoting a product or a service, and where to go to learn more about a company, typically the "about" area of the website. We discuss the function of an annual report and consider how the financial data can be somewhat incomprehensible except for those with business training. At this point, the difference 
between public and private companies is presented and linked to how company type affects access to information about the company. If time permits, students examine copies of the two respective versions (for public and private companies) of Hoover's Handbook. We discuss how public companies are required to disclose their financial situation to the Securities and Exchange Commission on a quarterly basis. We also discuss why the annual report of a public company is important to potential investors. The class becomes aware of the connection between access to information and legal requirements to disclose information. They relate this in turn to their projects (many of the companies that the students need to research for their assignment are private). Students also begin to consider why some information is transparent and easily available or why it is hidden.

Time is also spent looking at the news section of the company website, which some students, usually with my prompting, recognize as public relations fodder. We spend some time discussing how too much honesty about negative news would not be in the interest of the company, and, how in general, the company's website functions to make the company look its best.

The corporate website reflects reality in that it is ambiguous, authentic, and biased. Goad refers to "unbounded thinking" which removes traditional boundaries such as "using established formulas, addressing multiple realities, and using conflict as the basis of thought" (69). This indeterminate aspect is echoed by Collins who refers to the need for open-ended assignments because they reflect the reality of the workplace (1988, 61). The author's experience using only bogus websites in a website evaluation workshop was not very satisfying. In the literature on teaching students how to evaluate websites, Harley co-taught a semester-long freshmen seminar focused on critical thinking entirely around evaluating information, and used both bogus and non-bogus websites (303). Meola takes issue with the traditional checklist approach to evaluating websites. He also feels librarians are excessively critical of the open web lacking in standards (333). Wathen and Burkell examined how users consider websites credible. First, users consider if the website looks professional and if the information is easy to get. Then they consider if the source of the website is trustworthy or has credentials. Finally, they will evaluate content (141). Wathen and Burkell also note that the issue of likeability is also at play and goodwill of the source as well as familiarity with the source (136). Hospitality students at City Tech are fairly influenced by the cutting-edge, professional look of the company website as well as the cheery, civic-minded programs offered by the company.

Most students tend to be satisfied with the information they find on the company website and generally feel satisfied that their research is done. Meola argues that although students will use poor-quality websites, this does not mean that they use only poor-quality websites and/or lack the ability to evaluate sources/websites (334). At issue is the assignment itself as well as the expectations of depth and quality on both the part of the student and the teaching faculty member. Are students explicitly required to compare related, published sources to the website and to evaluate the website for audience, currency, authorship, bias and other qualities? 
The author tells the students that two key elements are missing in their research: sources external to the company website and highly current sources. When asked how to find current information on a company, some students suggest newspapers. At this stage, students locate any available external information about the company, such as recent news. In Lexis-Nexis, a simple search is performed on the company's name. Articles detailing the company's bankruptcy and other business crises constitute most of the news retrieved. Some students are aghast, and the entire library session is reframed. The energy in the classroom palpably shifts. We talk at length about what it means when a company is in Chapter 11: how the company is still operating and needs to continue to project a positive image via its website. When a company is bankrupt, workers may not get their paychecks or pensions, a new worker might be hired to replace multiple positions or to replace a more experienced worker, or the new employee might face layoffs (first hired, first fired) in the near future. Our hospitality students are strongly driven by vocational aspirations and the scenario of taking a position at a company in crisis can evoke strong reactions. Everyone knows someone who has been let go due to corporate downsizing.

We then go on to talk more generally about point of view and bias in information sources. Examples tend to come from the popular media as students are familiar with the idea of political bias in broadcast journalism. The conversation extends to how industry trade associations like the National Restaurant Association exist to further a very specific agenda and how that affects their research and how they represent the restaurant industry in their publications and website specifically.

Students are asked to explain how Google works. No student has ever successfully explained the underlying mechanism, although increasingly students are aware that websites can and do pay to get ranked higher. For the students who are not aware that companies can pay to be ranked higher, this information provokes indignant reactions and further advances critical thinking about the so-called objectivity of search engines.

After the Lexis-Nexis section of the workshop, different types of periodicals are covered in a show-and-tell style that includes and passing around the periodicals. Scholarly peerreviewed journals are also covered with an emphasis on how the peer review process is a way of vetting information. Students seem to have limited interest in this topic, and their waning attention is not improved by more lecture and less hands-on during this part of the session. However, peer review clearly reinforces the idea that not all information possesses the same quality. Publishing and the editorial process are described as well, and further connected to vetting and quality control. Copyright is briefly explained with some clarification of the limitations of access to materials. For example, students need to know that most published articles are not available on the World Wide Web and are available only through the library via paid subscriptions to periodicals and databases. Differentiating between published and non-published materials seems to be difficult for students.

Next, the class searches a business database to a find Datamonitor company profiles and a SWOT analysis (strengths, weaknesses, opportunities, and threats) of the 
company and compare how much easier these sources are to work with compared to the annual report on the company website. SWOT analyses are interesting tools for critical thinking because they are relatively simple to parse while not being value-neutral. Online catalog searches for books and other materials on the company conclude the session. Students are asked if they notice an issue with the search results which includes at least one very out-of-date book. The class always correctly identifies the issue of currency.

By staying with the same subject of research, the students are able to compare sources. Goad, in defining critical thinking, stresses comparison as well as comparing and contrasting. Even if students are limited in critical thinking about the content of different information sources, tracing a specific topic through different sources gives us opportunities to discuss how the sources and the related content vary. Meola refers to looking at data via different sources leading to comparative thinking that helps identify bias.

Some students consider, for the first time in their life, how different information sources have a point of view and an agenda, and how these sources need to be questioned and critiqued. It is this awareness that is one condition needed for life-long learning: the willingness to be receptive to learning and recognizing that learning happens all the time, everywhere, and throughout life. Jacobson and Xu talk about how students need to take their existing knowledge set and compare it to what is taught in the library workshop in order to create a new knowledge set $(2004,65)$. This library workshop gives students a good beginning on their path towards becoming aware of the need to learn and the need to find what is needed in order to learn.

\section{ASSESSMENT}

Assessment is a way to improve teaching methods and student learning when it does not function simply as a method of evaluation. Identifying clear student learning outcomes and developing a rubric to measure student learning is an assessment goal for the near future for this class. Another assessment goal is direct involvement with the post-workshop student work including a review of students' company profiles, and in particular, a review of the sources students used in their list of references.

In the first few years of this workshop, the teaching faculty member created a post-library session quiz. The quiz had one very simple yes/no question which was insufficient to determine if the students learned the bibliographic vocabulary that was such a major focus of the workshop. A revised quiz has been administered for four semesters, and student results are consistently very good for the multiple-choice questions relating to the bibliographic instruction vocabulary and concepts. To get a better sense of how students experienced these modifications in teaching, and to get a sense of student perceptions of the session, an open-ended, reflective question was added. Students are now asked to: "Reflect on what you learned in today’s library session and 
where you need to go next to become a more efficient and more sophisticated researcher.” Their responses vary tremendously from no response at all to responses showing that students recognize their own need to engage with the library and research.

\section{PROBLEMS AND OBSTACLES TO LEARNING}

Many students cannot evaluate sources because they lack critical thinking skills as well as reading comprehension skills (Sterngold and Hurlbert 1998, 248). However, other factors are at play as well. The main culprit seems to be Google. For students, the physical library has become irrelevant and library electronic resources require too much work to learn. Students, as well as their professors, often conceive of research as using Google. According to the De Rosa and OCLC's 2005 Perceptions of Libraries and Information Resources, 89\% of college students start their search via a search engine. Only $1 \%$ start their research via a library website or a library database (1-17). Just under $50 \%$ of college students completely agree that the library website is a source of worthwhile information as the college students surveyed do not generally trust purchased information more than free information. Today's Net Generation students obtain information on a "need-to-know" basis: most are not interested in research in and of itself. Students grossly overestimate their research skills, but they will readily admit that they get more irrelevant results than not and waste too much time searching and not finding. Google creates a false perception of mastery and completeness of content. Mastering use of the library website for research, unlike searching Google, takes time and effort to learn.

In addition to issues of basic literacy, many students may experience some kind of library anxiety. Kwon, Onwuegbuzie, and Alexander (2007) found a clear connection between library anxiety and weak critical thinking. Although they investigated graduate students of education, a majority of students is uncomfortable negotiating library resources, which, by their complexity and quantity, offer too many choices and decisions. New York City College of Technology offers over 100 electronic resources and databases.

Motivating students is very challenging, and even the threat of a quiz does not motivate some students. Even when the workshop is tied into their assignment, which is always a best practice, it is not a given that students are attentive. Jacobson and Xu note that the two most important factors in student motivation are that the library session is tied into an assignment that the students have already done some work on and the instructor's attitude towards the library workshop (12-13). Unfortunately, City Tech hospitality students usually have not started their research before their library session, which is typically very early in the semester. Also, how the instructor communicates about the value of the library workshop makes all the difference. Unless the instructor is enthusiastic about the library, students tend to interpret the library session as a lowpriority add-on. 
Life relevancy is extremely important for students on career tracks: Jacobson and Xu connect information literacy classes and student careers (40). However, if the teaching technique is traditional, as it was the first year or two of this workshop, all exhortations to pay attention because "you need to know how to research in order to get an interview, perform well enough on the interview to get the job and thrive on the job" often fell on deaf ears. In a far more in-depth, six-week group research project, in a seminar co-taught by a classroom faculty member and a librarian, Sterngold and Hurlbert did find that many students do connect their industry profile to their career (248).

\section{CHANGES IN TEACHING TECHNIQUES AND CONTENT}

Before using active learning techniques in the current class, the library workshop was primarily a lecture with some discussion. The universe of information sources available to students was covered as well as the difference between published and nonpublished sources. Peer-reviewed journals were also covered along with the show-andtell of periodicals and reference books. The class searched the same databases and catalog. Essentially the library resources covered were identical. Classes went fairly well if the classroom instructor was highly engaged and the students were relatively mature. However, the style of instruction created passive learning and the students digested what they could without any major shift in their understanding. The active learning teaching style, based on personal observation and feedback from the classroom instructor, really connects students. It connects them to the librarian as an instructor, connects them to the information literacy piece, and connects their experience to their professional aspirations. Another minor improvement is staying on the same exact topic; it provides more continuity and removes the barrier of revising the search strategy.

\section{CRITICAL INFORMATION LITERACY}

A call for critical information literacy is increasingly found in the library literature and noteworthy are Harley and Swanson (2004). Albitz's 2007 article provides a good overview of the literature and she notes that there is some confusion about the meaning of critical thinking in library literature (99-100). Some authors, including Doherty and Ketchner, focus on the profound political aspects of self-determination in learning that ensues when students become critical thinkers about information. Influenced by educator and political theorist Paulo Freire's "goal of social transformation through education," Doherty and Ketchner call for a radical revision of information literacy instruction that empowers the learner by "engaging students in the terms of students' own experiences." Swanson, on a more pragmatic level, states:

Before we train students to use search tools, before we send them to books, periodicals, or Web sites, we need to teach them about information. What is it? How is it created? Where is it stored? (260) 
Patricia Senn Breivik, an influential thinker on information literacy, also considers information literacy a type of critical thinking and not as a skills-based entity (Albitz 99).The problem, however, is that the expectation of a one-hour one-shot library workshop is to provide some basic search skills and familiarity with resources. This is a prime example of the need for information literacy to be more extensive and pervasive in the curriculum. It is problematic that teaching faculty and librarians use different terminology, and information literacy is not necessarily a part of the teaching faculty's language of pedagogy (Albitz, 98). On the one hand, critical thinking is understood as higher-level reasoning and does not necessarily involve information retrieval. Albitz articulates this disconnect:

The disconnect between the definitions of information literacy and critical thinking, which tends to fall along librarian, teaching faculty/administrative lines, foreshadows the differing opinions concerning which group should be responsible for teaching these overlapping skill sets, (Albitz, 101).

Grafstein also notes that the ideas of critical thinking and life-long learning, both heavily present in the library literature, are historically always placed within "purview" of classroom faculty (199).

\section{THE SOCIAL CONSTRUCTION OF KNOWLEDGE AND GROWING AWARE}

Latour and other social constructivist philosophers have advanced the idea that knowledge is socially constructed, fluid, and complex (1987). My first personal experience of critical thinking was tied into the idea of knowledge being socially constructed. In my high school history class, we did an active learning exercise comparing divergent newspaper accounts detailing the Soviet response to the Hungarian uprising in 1956 from the New York Times and Pravda. The experience was transformative. Bruckman feels that students cannot navigate the online environment and begin to grow information literate without understanding the social construction of "truth": how an insight is asserted by an individual or small group and then becomes socially accepted. Understanding the social construction of truth requires higher-level thinking than what occurs in my bankrupt company exercise. However, my exercise is on the beginning end of the continuum of self-questioning and metacognition that engenders critical thinking.

\section{ACTIVE LEARNING}

The Arizona Faculties Council defines learner-centered education as one that ... places the student at the center of education. It begins with understanding the educational contexts from which a student comes. It continues with the instructor evaluating the student's progress towards learning objectives. By helping the 
student acquire the basic skills to learn, it ultimately provides a basis for learning throughout life. (Arizona Faculties Council 2000)

To reiterate, active learning and learner-centered education teach students how to learn.

Bruce's idea of relational information literacy focuses on the student's perspective.(1997). Doherty and Ketchner acknowledge that it is difficult to work with freshmen as their prior educational experiences may not have prepared them for active learning. Their previous learning experiences often were centered around listening to classroom lectures. However, students' first experiences with active learning are all the more powerful because they feel empowered in their learning experience for the first time. Active learning techniques are challenging to use because so much depends on student response and dynamics. Issues of control of the classroom in active learning are often at play: teaching faculty do not have total control when they invite students to participate actively (Gradowski, Snavely, and Dempsey 1998, viii). In the case of this workshop, the teaching librarian maintains overall control of the classroom, but student responses vary greatly and are unpredictable. There are other ways to intensify the active learning aspects of the workshop. Since many students may be reticent to volunteer their comments or opinions, students could be placed in small work groups to analyze the corporate website. The librarian provides guidelines to the students who then report back their responses to the entire class for a discussion of their findings.

\section{HOSPITALITY MANAGEMENT PEDAGOGY AND THE LIBRARY}

Critical thinking, and, to a much lesser degree, information literacy have both been identified as skills and modes of thinking which have been essential to the hospitality management workforce since the 1980s. It is telling, however, that the Accreditation Commission for Programs in Hospitality Administration, in their Handbook for Accreditation (2004), views the library largely as a facility of resources and has no mention of information literacy or library instruction in their accreditation process. In the literature of hospitality management pedagogy, Sivan et al. describes student responses to a series of active learning exercises. "Activities that had no direct link with industry were rated much lower: examples included life cycles and library exercises” (387). The author does not specify exactly what kind of library exercises occurred. The library literature has a good number of articles on discipline-specific information literacy instruction but lacks discussion of the needs of hospitality management students as well as other trade and vocational areas. The closest body of literature is on information literacy for business and marketing.

\section{HOSPITALITY MANAGEMENT INDUSTRY NEEDS}


Sigala and Baum characterize the current hospitality industry as "information intensive" (2003, 368). Traditionally, hospitality management was considered a craft enterprise and/or a service-oriented field. Today, the field requires managerial abilities together with information handling skills. In hospitality management education, there is a tension between the traditional focus and new orientations.However, Sigala and Baum believe that hospitality management education provides too great a focus on traditional technical skills (2003, 369).

Employers who hire hospitality graduates want employees with problem-solving skills, not skills or knowledge per se (Collins,59). Many people problem-solve with a solution in mind, thus not fully exploring all aspects of the problem and not asking enough questions (Haywood 1987, 53). Students often are taught with a casemethodology that supplies the information needed. Alternatively, students already have the knowledge base from their education to basically solve the problem. In reality, however, every problem is unique and often requires investigation and research. Because some students have poorly developed critical thinking skills, they may be weak in recognizing when they need information and when they need to do research (Haywood,54).

Guests and travelers (and other customers and clients) are increasingly sophisticated and have more complex needs. The hospitality workplace is highly mutable, and employment is no longer fixed or stable. Employees need to be engaged learners who can recognize trends and other forms of change in order to respond to a constantly evolving profession (Sigala and Baum, 369-370). Globalization has created multicultural and multinational workplaces and customers. As a result, employees require more sophisticated collaborative and communication skills.

\section{CONCLUSION}

This workshop will always be a work in progress. If more than one hour was available to teach students about library research, the possibilities for more extensive student evaluation of sources and critical thinking exercises would greatly increase. However, this scenario is highly unlikely and the most likely way to reinforce and expand student critical thinking about information would be to collaborate with faculty in creating an assignment.

A postscript: the author recently completed teaching workshops for all sections of the introductory hospitality management course. Fall 2007 freshmen students are markedly more sophisticated about information and participate in classroom discussion in much greater numbers. The students continue to be satisfied with the company website as their only source, but increasingly, classes are conscious of the importance of other sources and aware of bias. The recent increase in student enthusiasm for the library workshop is highly rewarding. 
Parts of this article were originally presented at the $2^{\text {nd }}$ Annual CUNY General Education Conference, "General Education in the Disciplines and Professions: New Approaches to Old Debates," Queensborough Community College, Bayside, NY, May 5, 2006

\section{REFERENCES}

Accreditation Commission for Programs in Hospitality Administration. 2004. Handbook of accreditation. Oxford, MD. http://www.acpha/cahm.org/forms/acpha/ acphahandbook04.pdf.

Albitz, R, S. 2007. The what and who of information literacy and critical thinking in higher education. Portal: Libraries in the Academy 7:,97-109.

Arizona Faculties Council. 2000 Arizona Faculties Council (AFC) definition of learnercentered education. http://www.abor.asu.edu/4_special_programs/lce/afcdefined_lce.htm.

Bruckman, A. S. 2005. Student research and the Internet. Communications of the ACM 48: 35-37.

Bruce, C. 1997. Seven faces of information literacy in higher education. http://sky.fit.qut.edu.au / bruce/inflit/faces/ faces1.htm.

Collins, J. 1988. The library: Learning lab for managers." Cornell Hotel and Restaurant Administration Quarterly 29: 59-61.

De Rosa, C, and OCLC. 2005. Perceptions of libraries and information resources. Dublin, OH: OCLC. http://www.oclc.org/reports/2005perceptions.htm.

Doherty, J. J. and K. Ketchner. 2005. Empowering the intentional learner: A critical theory for information literacy instruction. Library Philosophy and Practice 8: 110. http://libr.unl.edu:2000/LPP/doherty-ketchner.htm.

Goad, T. W. 2002. Information literacy and workplace performance. Westport, CT: Quorum Books.

Gradowski, G., L. Snavely and P. Dempsey. 1998. Designs for active learning: A sourcebook of classroom strategies for information education. Chicago: The Association of College and Research Libraries.

Grafstein, A. 2002.A discipline-based approach to information literacy. Journal of Academic Librarianship 28: 197. 
Harley, B. L. 2001. Freshmen, information literacy, critical thinking and values. Reference Services Review 29: 301-306.

Haywood, K. M. 1987. Thoughts on thinking: A critical human-resource skill." Cornell Hotel and Restaurant Administration Quarterly 28: 50-55.

Jacobson, T. and L. Xu. 2004. Motivating students in information literacy classes. New York: Neal-Schuman Publishers.

Kwon, N., A. J. Onwuegbuzie and L. Alexander. 2007. Critical thinking disposition and library anxiety: Affective domains on the space of information seeking and use in academic libraries. College \& Research Libraries 68: 268-278.

Latour, B. 1987. Science in action: How to follow scientists and engineers through society. Cambridge, MA.: Harvard University Press.

Meola, M. 2004. Chucking the checklist: A contextual approach to teaching undergraduates web-site evaluation. Portal: Libraries in the Academy 4: 331-344.

Sigala, M. and T. Baum. 2003. Trends and issues in tourism and hospitality higher education:Visioning the future. Tourism \& Hospitality Research 4: 367.

Sivan, A. et al. 2000. An implementation of active learning and its effect on the quality of student learning. Innovations in Education \& Training International 37: 381-389.

Sterngold, A. H. and J. M. Hurlbert. 1998. Information literacy and the marketing curriculum: A multidimensional definition and practical application. Journal of Marketing Education 20: 244-249.

Swanson, T. A. 2004. A radical step: Implementing a critical information literacy model. Portal: Libraries in the Academy 4: 259-273.

Wathen, C. N. and J. Burkell. 2002. Believe it or not: Factors influencing credibility on the Web. Journal of the American Society for Information Science and Technology 53: 134-144. http://dx.doi.org/10.1002/asi.10016. 